DOI: 10.20472/IAC.2017.031.022

\title{
SUKANYA KEMP
}

University of Akron, United States

\section{IRINA CHERNIKOVA}

University of Akron, United States

\section{AN ALTERNATIVE LOOK AT MEASUREMENT OF UNIVERSITY PERFORMANCE IN STEM EDUCATION: A DATA ENVELOPMENT ANALYSIS PROJECT}

\begin{abstract}
:
How is success measured in the field of STEM education in US universities? Such a question can be difficult to answer because of the lack of uniformity among the relevant variables. Given the wide diversity in success indicators, and the fact that universities choose to pursue different aspects of educational outcomes, it is often difficult to compare performances and definitively point to one school as 'better' than another.

IIn an attempt to measure university efficiency in the areas of engineering, natural, physical and health sciences, the authors use the non-stochastic frontier model of Data Envelopment Analysis (DEA), which is commonly used in Operations Research literature, to evaluate the efficiency of producers. In this initial research, the authors isolated the large public universities of Ohio as the subject of the analysis. They found that with the input-output structure defined by the data, certain universities clearly stood out as efficient compared to others in the dissemination of STEM education. A logistic regression isolated the inputs and outputs that had the strongest effects on the efficiency scores.
\end{abstract}

\section{Keywords:}

STEM education, University Performance, Data Envelopment Analysis, Efficiency

JEL Classification: A00, C67 